\title{
Formatting the Public Sector with ICTs: Exploring Institutional Sources and Processes
}

\author{
Noora H. Alghatam \\ Information Systems and Innovation Group, \\ London School of Economics and Political Sciences, London, United Kingdom \\ n.h.alghatamalse.ac.uk
}

\begin{abstract}
This paper discusses the process in which e-government projects are initiated and locally negotiated within the public sector organizations. The issue is explored by employing the theoretical concept of global formats. The concept of formats is employed to explore two interlinked themes: the institutional sources for e-government projects and the processes of locally appropriating these projects within the organizational setting. This paper focuses on an egovernment project that was successfully implemented in one of Dubai's public sector organizations.
\end{abstract}

Keywords: e-government, global formats, institutions, information systems implementation.

\section{Introduction}

E-government projects have been adopted in both developed and developing countries as a means to reform the public sector, and as part of a broader objective of achieving social and economic sustainability goals [1], [4], [7], [9], [13], [26]. This paper does not focus in particular on the implications of e-government in contributing to development; rather the aim is to explore how the projects that are part of these national initiatives are locally understood, encountered and appropriated by people who work in the public sector.

Institutional arrangements play a role in shaping how the planning, design and use of ICTs in the public sector is enacted [11], [16]. Similarly, some academics discuss e-government in terms of the historical developments in the public sector and policies of New Public Management (NPM) [10], [15], [16], [19]. For instance, e-government is conceptualized as an extension to a history of NPM initiatives in the west [19]. These initiatives are also considered to be the mark of the digital era governance where information and communication technologies (ICTs) can resolve the problems associated with NPM initiatives of the past [15]. Adopting an institutional lens explains why there are challenges in adopting standardized systems and models, and why there is diversity in the outcomes [3]. For example, we often find in the case of developing countries that the ICTs adopted are inscribed with values and assumptions that originate from other contexts, which Heeks refers to as the design-actuality gap 
[20]. Such mismatches between e-government systems and contexts are also depicted in the work of Cordella and Iannacci who present the case of an e-government project in the justice department in the United Kingdom and Wales. The authors employ institutional theory to explain how implementation involved building on an existing system that was inscribed with concepts from past NPM initiatives and notions of decentralization [10].

Studies that examine e-government projects from an institutional lens often focus on whether e-government systems have become institutionalized or not [6], [25]. There is not enough work that explores the nature of institutional interplay and how it conditions the micro-level process of implementation [6]. There are a few studies that have adopted Actor Network Theory and concepts of improvisations to explore this process [5], [21]. In this paper, the theoretical concept of formats [27] is employed to explain how semi-configured packages arrive with e-government projects, and how local actors in the public sector work on appropriating them to fit within existing institutional arrangements.

The research question addressed here is: how are e-government projects experienced, negotiated and localized in the context of the public sector organization? The main argument presented is that e-government projects are shaped by interplay between historical developments and the semi-configuration of formats. This combination sets in motion (and conditions) a series of interactions within the organization that localizes e-government.

The paper consists of seven sections. The paper began with an overview of egovernment studies and the research question. The second section introduces the theoretical concept of formats. The third section is the methodology. The fourth section presents an overview of the case study of Dubai's e-government initiative. The fifth section presents the findings, and the sixth a discussion of the key themes that are guided by the theoretical concept of formats. The paper concludes with a summary and key findings.

\section{Theoretical Framework: Global Formats}

The concept of formats refers to a semi-configured arrangement of institutional norms, modes of organizing and technology that are (in part) designed by powerful institutional actors and the discourses they engage in. Sassen [29] identifies these three elements when she states that a format "... is precisely at the intersection of the technology and the organizational forms and norms".

Technology is at the heart of these formats, because artifacts bring relevant institutional norms and modes of organizing. It is through this technological component that formats arrive into the organizations and gain legitimacy for adoption and use, mainly because ICTs are associated with transformation, modernization and efficiency gains. As noted by Sassen [28], formats require the invention of tools to support their activities and, in the case of e-government, this can be the code, the infrastructure, the work supporting software, or the web portal. The technology component is enacted within 
organizations and is shaped through use: “...technology is mutant and indeterminate and its potential is performative if other variety of variables are there" [27].

In relation to mode(s) of organizing, international, regional and national institutional actors influence most organizations when they plan, develop and use ICTs. Latham and Sassen describe this in the context of CSO as "...a variety of non-state actors and forms of cross-border cooperation and conflict - global business networks, the new cosmopolitanism, NGOs, Diaspora networks, and trans-boundary public spheres" $[23$, p. 22, 23]. As the authors explain, the involvement of these actors is understood to be an established hierarchy of scale. For example, in the case of egovernment projects, there are various international organizations or management consultancies that play a role in the practices adopted. The new modes of organizing include working in ways that conform to the best practices such as the stages of growth models and implementation strategies that these institutional actors promote in presentations and publications on e-government.

Finally, the concept of formats incorporates new institutional norms surrounding the development and use of technology. For example, most e-government projects respond to the institution of NPM, which is strongly associated with e-government. Such an institution sets expectations on how the public sector staff perform, specifies the roles of the staff members as they work on e-government, and frames what is deemed to be a successful implementation. For example, it is common in such projects to consider clients who interact with the public sector as 'customers'.

\section{$3 \quad$ Methodology}

The empirical part of this study focuses on the e-government project in one of Dubai's largest public sector organizations for the period of 2000-2008. The empirical research began with a preparatory study in October 2006 that included five interviews to learn more about the e-government initiative and the kind of projects that were being implemented. During this time, interviews were conducted with IT managers from various government departments, the central government organization for egovernment and a researcher from a research institution in Dubai. This provided insight into the developments of the project since year 2000 that included the institutional structures of the state that were set up to plan and manage the e-government initiative. Shortly after that, from October 2006 to May 2007, several visits were made to the main research site, each visit lasting up to one week. The author mainly focused on the e-government section, which is part of the IT department and where the IT managers, system analysts, developers and support officers worked on the egovernment systems.

The research design was a single case study and the data collection methods were mainly based on semi-structured interviews and on-site observations [33], [34]. Following the interpretivist approach to research, the fieldwork was shaped by the interpretations of the researcher in the field as she attempted to capture the actors' perspectives [8], [31], [32]. The interviews were based on the themes of: the history of the project; the nature of the planning and development activities; the ICT staff's early expectations of e-government; challenges encountered during the project and 
finally any changes to the nature of operations in the public sector. The interviews were based on a list of questions that guided the interview process to a large extent. However, the nature of qualitative research enabled the researcher to follow up certain themes with questions and shift focus [8]. The interviews were in Arabic or English depending on the interviewee's nationality or preference. The researcher took notes and sometimes tape recorded the interviews.

In addition to interviews, other data collection methods were employed. For example, there were notes taken about the overall work environment, which included the office spaces and work activities of the ICT staff. Secondary data were collected and reviewed during fieldwork to inform the interview process. The researcher reviewed technical specification documents for the systems, job descriptions of the ICT staff and presentations by management consultants. The researcher also read articles published by the central government agency Dubai eGovernment Department (DeG) about the e-government initiative.

\section{Case Description}

The e-government project that is the focus of this paper was in one of Dubai's largest public sector organizations, which we will refer to in the paper as The Public Office, abbreviated as TPO. The project is part of a large national e-government initiative to modernize and transform the public sector through the employment of ICTs, and specifically the Internet, in the provision of public services. The initiative was officially announced in the state media in the year 2000 and this set a clear deadline for public organizations to set up $70 \%$ of their services over the Internet within a timeframe of a year-and-a-half. The target later changed to $90 \%$. There were two main objectives specified: creating convenience and positioning Dubai as an economic hub for the region. During that year a contract was signed with an international consultancy to assist in the initiative. The consultancy provided guidance in a pilot project to develop four systems and that involved a number of public organizations. Later the consultancy was involved in the design of three institutional structures for the state to plan and manage the e-government initiative, which are: the executive office, Dubai eGovernment and the Government Information Resource Planning Department. Table 1 presents an overview of the role and some of the activities of these institutional structures. Over time these institutional structures took over the planning role off the management consultancy.

TPO was faced with the dilemma of limited experience and expertise in web-based technologies and a strict deadline. There was not enough time to learn and work independently on the project, so a contract was signed with an IT and management consultancy that had international expertise in e-government projects. The focus of the study is on the development of the online applications for public services that were to be provided on the web portal, and not the development of back-end systems. One of the first actions taken by the management consultants was to conduct an assessment study of the organization's 'readiness' to embark on the project. Later, they provided a conceptualization on how the project would progress towards the state's deadline. The 
plan was based on the service prioritization model, which suggests beginning with the simple services first and then gradually progressing to the more complex ones.

The later stage of the model refers to services that require the development of interorganizational systems to integrate work processes with other public sector organizations. The plan was that the systems were implemented over four phases. The project conformed to the best practice model and plan, and an IT service provider team was hired to work in the IT department to conduct most of the development of applications. The internal team in TPO was expected to work on the support of these services, later taking up a bigger role in the development of applications. It was only a matter of time until bugs were found in the systems that disrupted their operation. The internal team was worried about the situation and in response developed a coding template and checklist to improve the coding process and documentation. A pilot of the new template was developed and presented to IT managers in the department who agreed on introducing it to improve the development process. There were fewer bugs in the systems reported after the new template was adopted in phases three and four. The internal IT team worked on recoding the older applications that were problematic. TPO's system met and even surpassed the state deadline. During phase four, a new project to develop a new infrastructure was introduced to allow flexibility in design. This required additional work in coding the online applications.

Table 1. An Overview of Institutional Structures for E-government in Dubai

Institutional Structures

The Executive Office

Dubai eGovernment (DeG)

Government Information Resource and Planning Department

\section{Objectives}

Responsible for formulating the strategy for e-government, and the vision and mission for DeG

Promote e-government to the public to reduce physical visits to public sector organizations.

Assist in the simplification of business processes for the development of online services.

Assist the public sector organizations in transitioning towards the integration of databases across different organizations.

Ensure there is a single access point for government services.

Responsible for the set up and management of the technical infrastructure for the e-government initiative.

Source: Interview with a former manager at DeG in December 2006 [14], [30] 


\section{$5 \quad$ Findings}

\subsection{The Context: History, City Development and ICTs}

Revisiting the early phases of setting up of the public administration in Dubai, and the United Arab Emirates (UAE) as a whole in the early 1970s, reveals a series of efforts to build and modernize public systems. It was also apparent that ICTs acquired a significant role in these initiatives in later years. There were numerous investments made in human and financial resources to set up an operable public administrative system in the early 1970s upon attaining independence and the formation of the federation [12], [35]. Dubai's economic activities at the time coincided with one of the earliest efforts in the region to set up a system to support the development of the state and its operations. As the region's social and economic activities expanded, particularly with the exports of oil and industrialization, there was a need to improve the public administrative systems to support this [12], [17], [18].

In the 1980s there were programs set up with international organizations such as the United Nations Development Programme (UNDP) to provide guidance and consultation to improve the operations of the public administrative systems. The outcome of the UNDP study was mainly in relation to human resource recruitment and training [22]. Following on this pattern, there were computerization initiatives for data storage and improving levels of efficiency. The significance of employing ICTs in improving the functioning of the public sector is still present today. The main difference with egovernment in Dubai is the stronger emphasis on the transformation of operations and the creation of a relationship between the public and the public sector that is more customer-oriented [2].

\subsection{The Arrival and the Acceptance of the E-government Format}

The e-government format, which was in part shaped by global discourses and semiconfiguration, was introduced into TPO through three institutional actors. One of the most significant events was the initial announcement of the electronic government initiative in Dubai in 2000. The state mandate for e-government specified objectives for the public sector. They were expected to set up $70 \%$ of public services over the Internet within a time frame of 18 months. Moreover, the e-government initiative was framed as a means to make it more convenient for all those who interact with the public sector. Another objective of the initiative was to support Dubai in positioning itself as an economic hub for the region. The emphasis on creating convenience in the public sector is linked to a history of managerial ideas and practices in the UAE. There were various efforts over the years to improve and modernize the public sector since the 1980s by focusing on quality and initiating privatization projects.

Second, the e-government initiative established three institutional structures to plan and manage the e-government initiative across the public sector, which were outlined in Table 1. The central agency DeG played a pivotal role in managing the way these systems were developed by providing key performance indicators and evaluating progress based on quarterly reports that were sent to them. DeG was also involved in 
communicating objectives about the project to various actors in the public sector through presentations. These presentations often included framing expected progress in the e-government initiative in terms of criteria in the stages of growth models.

Third, the e-government project involved working in collaboration with the private sector. The management consultants provided guidance and a plan and the IT service provider worked with them in the development of online applications for the web portal. The involvement of the private sector instantiated and supported the managerial approaches and concepts introduced into the public sector. One of the most significant was the service prioritization model that in essence was based on international best practices.

\subsection{Localizing E-government}

At this point we focus on the process of localizing these systems, which resulted from the actions of the ICT staff in TPO, and which were conditioned by interplay between old and new institutional elements. This section presents three examples of such actions taken by the ICT staff and how they link to institutional elements of the public sector or the new format.

The first example is when the ICT manager registered the e-government project in one of the online competitions offered by an international organization. The action was driven by a sense of ambiguity and the relative newness of these projects, as well as an aspiration to find guidelines on how these projects are developed and evaluated according to global criteria. The act of signing up to the competition shows the influence of international best practices and managerial models in the public sector.

However, there are also examples of the e-government format not fitting with institutionalized dimensions of the public sector. For instance, the emphasis of using standardized models during the planning of the project does not account for local pragmatic concerns of the public sector staff. This was evident when the service prioritization model, which suggests working on simple services first, was not conformed to during the planning of the systems. Instead the managers who were working on e-government took the decision to go ahead with developing a complex inter-organizational system early on. This was because the manual system was a problem that the public and the business community were facing and it needed to be resolved quickly. Another example was the new work arrangements that involved cooperation with the IT service provider that had international expertise and the situation of finding bugs in the system. The internal ICT team in TPO introduced a coding template and checklist to improve the quality of the coding. The semi-configured nature of the format is expected to generate standardized outcomes, and to shape the understanding of e-government implementation. The two examples presented here illustrate that local actors appropriate elements of these formats in ways that come to shape how the systems are developed. 


\section{Discussion}

The earlier section described key events that took place during the implementation of the e-government project that involved improvisation and innovation during work. This section elaborates on two themes: institutional sources of e-government and the design and shaping of formats. These themes discuss the process of localizing the egovernment systems.

\subsection{Institutional Sources of E-government}

Revisiting e-government formats that arrive in the public sector consists of understanding elements from early generations of e-government as well as NPM. NPM in the west has been influential since the 1970s in the adoption of ICTs in the public sector with the aim of improving efficiency and creating a client culture. Similar trends were present in the UAE, which has initiated programmes to modernize the public administrative system since the 1970s and 1980s that included computerization programmes. As such, e-government initiatives are seen as an extension to the history of automation of work processes to the current initiative to set up web-based systems and the provision of services to create convenience for the public. Yet, there are features to e-government that make it distinct from the previous initiatives. Egovernment emphasizes the theme of transformation of the public sector when it comes to service delivery and relationships with the public. Also, unlike ICT use within NPM initiatives, e-government positions ICT as a central component of change, and not at the periphery. This emphasis on the significance of ICTs introduces with e-government a package of standardized models and approaches to plan, develop and evaluate these systems.

As noted in the previous section, e-government formats that arrive are supported by disembodied institutions that include international organizations and IT and management consultancies [3]. These institutions provide legitimacy to the e-government project since it is associated with organizational change and socio-economic objectives. In addition to this, local institutions in Dubai's public sector conditioned local actors to accept e-government and took actions that localized the systems. As noted earlier, the ICT staff adapted the service prioritization model and developed a coding template and checklist to meet pragmatic concerns in the public sector. These actions also conformed to the institutionalized role of the public sector as a contributor to development. Thus, the e-government format (the semi-configured package) is intertwined with the historical developments in Dubai's public sector. It came to inform the actions of the ICT staff to localize the system.

\subsection{Between the Design and Shaping of Formats}

E-government projects introduce common objectives and practices to develop and use these systems. Even perceptions of success and failure are defined in similar ways that are guided by best practice models. This is partly from the influence of the private sector and international organizations, which promote similar managerial 
approaches to ICT projects. These formats for e-government are semi-configured at both the global and national level and thus there is room for locally determining their content to meet local needs and priorities. For example, there are state policies that determine the objectives of these projects, and which element (technology, modes of organizing or new norms) is the central one through which these initiatives are introduced, supported and granted legitimacy. This is illustrated when state policies determine how the systems are to be developed: a new system that is developed from scratch or a system that is built on an existing legacy system, built in-house or outsourced.

As this paper has discussed, e-government formats are also constantly shaped as people in organizations engage with their elements. For instance, some elements are accepted such as the concept of considering the client as 'the customer'. There are other elements of the format that compete with institutionalized dimensions of the public sector and create puzzles that need to be resolved. As the case study has shown, the ICT team adapted elements of the format when they encountered these puzzles and drew upon the historical role of the public sector in development.

\section{Conclusion}

This paper focuses on how an e-government project in Dubai was negotiated and localized through the actions of the people working on planning and developing the systems. The paper consists of seven sections. The paper begins with an overview of e-government studies and presented the research question addressed here, which is: how are e-government projects locally experienced, negotiated and localized within the context of the public sector organization? The second section presented the theoretical framework of formats and described its main constructs. The following two sections were the methodology and case study sections that described fieldwork activities and an overview of the public sector in Dubai and the e-government initiative.

The findings section presents a narrative of the developments over the course of the project including an overview of the historical context of the public sector in Dubai and the role of ICTs in city development. The section following this discusses the arrival of the e-government format and its acceptance in the public sector. Finally, the section presents findings within the context of TPO, where local staff encountered the e-government format and took action to localize the e-government systems.

The paper then discusses why actions were taken to localize the systems by drawing on some themes from the theoretical concept of formats. It begins by discussing the institutional sources of e-government in the UAE and then the institutional dynamics that come to inform actions in e-government project. On the one hand, there is the design of formats. On the other, there is ongoing negotiation and shaping of these formats as people encounter new ideas, concepts and artifacts that compete with institutionalized dimensions of the public sector.

In summary, this paper has shown that the e-government format introduced new institutional elements of NPM, and early generations of e-government, into the public sector organization TPO. The public sector employees encountered and appropriated 
these elements into their daily work activities. In the organizational context, the ICT staff's acceptance of the e-government project, and the efforts to make it work through localization, reflects an ongoing interplay between the historical dimensions of the public sector in Dubai and the new e-government format. As illustrated in this paper, these dynamics are most evident during subtle breakdowns in the project and contradictions that required the ICT staff to resolve them.

\section{References}

1. Andersen, K., Henriksen, H.: E-government Maturity Models: extension of the Layne and Lee model. Government Information Quarterly 23(2), 236-248 (2006)

2. Arif, M.: Customer Orientation in e-Government Project Management: a case study. The Electronic Journal of e-Government 6(1), 1-10 (2008)

3. Avgerou, C.: Information Systems and Global Diversity, 1st edn. Oxford Univer-sity Press Inc., New York (2002)

4. Avgerou, C., et al.: Interpreting the Trustworthiness of Government Mediated by Information and Communication Technology: lessons from electronic voting in Brazil. Information Technology for Development 15(2), 133-148 (2009)

5. Azad, B., Faraj, S.: Making E-Government Systems Workable: Exploring the evolution of frames. The Journal of Strategic Information Systems 17(2), 75-98 (2008)

6. Azad, B., Faraj, S.: E-Government Institutionalizing Practices of a Land registration mapping system. Government Information Quarterly 26(1), 5-14 (2009)

7. Baum, C., Di Maio, A.: Gartner's Four Phases of E-government Model. Stamford, Ct., Gartner Group 21, 12-6113 (2000)

8. Bryman, A.: The Debate about Quantitative and Qualitative Research: a question of method or epistemology? British Journal of Sociology 35(1), 75-92 (1984)

9. Ciborra, C., Navarra, D.: Good Governance, Development Theory, and Aid Policy: risks and challenges of e-government in Jordan. Information Technology for Development 11(2), 141-159 (2005)

10. Cordella, A., Iannacci, F.: Information Systems in the Public Sector: the e-Government enactment framework. The Journal of Strategic Information Systems 19(1), 52-66 (2010)

11. Coursey, D., Norris, D.F.: Models of E-government are they Correct? an empirical assessment. Public Administration Review 68(3), 523-536 (2008)

12. Davidson, C.: The United Arab Emirates: A Study in Survival. Lynne Rienner Publishers, Boulder (2005)

13. Davison, R.M., Wagner, C., Ma, L.: From Government to E-government: a transition model. Information Technology and People 18(3), 280-299 (2005)

14. Dubai eGovernment: Dubai e-Government: Achievements and Lessons Learnt. UNDP Presentation (2005)

15. Dunleavy, P., et al.: New Public Management Is Dead-Long Live Digital-Era Governance. Journal of Public Administration Research and Theory 16(3), 467-494 (2006)

16. Fountain, J.: Building the Virtual State: Information Technology and Institutional Change. Brookings Institution Press, Washington, DC (2001)

17. Fox, J., Mourtada-Sabbah, N., Mutawa, M.: The Arab Gulf region: traditionalism globalized or globalization traditionalized? In: Fox, J., Mourtada-Sabbah, N., Mutawa, M. (eds.) Globalization and the Gulf, pp. 3-60. Routledge, New York (2006)

18. Heard-Bey, F.: The United Arab Emirates: statehood and nation building in a tradi-tional society. The Middle East Journal 59(3), 357-375 (2005) 
19. Heeks, R.: Reinventing Government in the Information Age: International practice in ITenabled public sector reform. Routledge, London (1999)

20. Heeks, R.: E-Government as a Carrier of Context. Journal of Public Policy 25(1), 51-74 (2005)

21. Heeks, R., Stanforth, C.: Understanding e-Government project trajectories from an ac-tornetwork perspective. European Journal of Information Systems 16(2), 165-177 (2007)

22. Jakka, A.: Client-Quality Dimensions: empirical evidence from the public sector of the United Arab Emirates. Public Organization Review 4(3), 239-257 (2004)

23. Latham, R., Sassen, S.: Digital formations: constructing an object of study. In: Lat-ham, R., Sassen, S. (eds.) Digital Formations: IT and New Architectures in the Global Realm, pp. 1-33. Princeton University Press, New Jersey (2005)

24. Layne, K., Lee, J.: Developing fully functional E-government: a four stage model. Government Information Quarterly 18(2), 122-136 (2001)

25. Luna-Reyes, L.F., et al.: Information Systems Development as Emergent Socio-technical Change: a practice approach. European Journal of Information Systems 14(1), 93-105 (2005)

26. Okot-Uma, R.W., London, C.S.: Electronic Governance: re-inventing good governance. Commonwealth Secretariat, London (2000)

27. Sassen, S.: Constructing the Digital Object of Study. In: The 6th Social Study of IT workshop at the LSE in Celebration of Claudio Ciborra, London School of Economics and Political Science, London (2006a)

28. Sassen, S.: Forward. In: Dean, J., Anderson, J., Lovink, G. (eds.) Reformatting Poli-tics: Information Technology and Global Civil Society. Routledge, New York (2006b)

29. Sassen, S.: Personal communication with author via email (2006c)

30. Sethi, N., Sethi, V.: E-government Implementation: a case study of Dubai e-government. E-governance in Practice, pp. 185-195 (2009) (online), http: / /www.csi-sigegov.org/egovernance_pdf / 22

31. Van Maanen, J.: Qualitative Studies of Organizations. Sage Publications, Thousand Oaks (1998)

32. Walsham, G.: Interpreting Information Systems in Organizations. John Wiley \& Sons, New York (1993)

33. Yin, R.: The Case Study Crisis: some answers. Administrative Science Quarterly 26(1), 58-65 (1981)

34. Yin, R.: Case Study Research: Design and methods. Sage, Thousand Oaks (1994)

35. Zahlan, R.S.: The Origins of the United Arab Emirates. St. Martin's Press, New York (1978) 